\title{
Novel targeted agents for gastric cancer
}

\author{
Lian Liu', Ning $\mathrm{Wu}^{3}$ and Jin $\mathrm{Li}^{1,2^{*}}$
}

\begin{abstract}
Contemporary advancements have had little impact on the treatment of gastric cancer (GC), the world's second highest cause of cancer death. Agents targeting human epidermal growth factor receptor mediated pathways have been a common topic of contemporary cancer research, including monoclonal antibodies (mAbs) and receptor tyrosine kinase inhibitors (TKIs). Trastuzumab is the first target agent evidencing improvements in overall survival in HER2-positive (human epidermal growth factor receptor 2) gastric cancer patients. Agents targeting vascular epithelial growth factor (VEGF), mammalian target of rapamycin (mTOR), and other biological pathways are also undergoing clinical trials, with some marginally positive results. Effective targeted therapy requires patient selection based on predictive molecular biomarkers. Most phase III clinical trials are carried out without patient selection; therefore, it is hard to achieve personalized treatment and to monitor patient outcome individually. The trend for future clinical trials requires patient selection methods based on current understanding of GC biology with the application of biomarkers.
\end{abstract}

Keywords: Gastric cancer, Targeted therapy, Monoclonal antibody, Tyrosine kinase inhibitor

\section{Introduction}

GC remains a major cancer burden across the globe. In 2008, approximately 989,000 new cases (7.8 \% of global cancer totals), and 738,000 deaths (9.7\% of global cancer totals) occurred, making it the fourth most common malignancy and the second leading cause of cancer death worldwide[1]. Geographically, Asian and South American countries have a higher incidence rate of GC than the United States and Western Europe. Though the absolute incidence of GC has declined globally in the second half of the 20th century, the relative incidence of proximal GC has increased notably [2].

Traditional treatments, such as curative surgery, radiotherapy, and perioperative chemotherapy, may improve the survival rate of operable GC patients. However, most patients are either diagnosed at an advanced stage or are subject to relapse after prior curative surgery. For these advanced patients, 5-FU (5-fluorouracil) cisplatin, or their analogs remain standard treatment regimens, with or without an anthracycline [3].

\footnotetext{
* Correspondence: fudanlijin@163.com

'Department of Medical Oncology, Fudan University Shanghai Cancer Center, Shanghai 200032, China

${ }^{2}$ Department of Oncology, Shanghai Medical College, Shanghai 200032, China

Full list of author information is available at the end of the article
}

In the past decade, targeted therapies have significantly impacted the treatment strategy of many common malignancies, including breast, colorectal, and lung cancers. Unfortunately, research shows fewer encouraging targeted treatments for GC than for other cancers. Recently, Trastuzumab has been approved as standard care for HER2-positive GC patients, according to the results of clinical trials using ToGA (Trastuzumab for Gastric Cancer) [4]. Many other molecular targeted agents are also currently undergoing clinical trials, including VEGF pathway targeting agents, other HER family targeting agents, mTOR pathway inhibitors [5], and histone deacetylase (HDAC) inhibitors [6]. This review discusses recent investigations of targeted agents for the treatment of advanced GC.

\section{The Pathway of Targeted Therapy}

Based on clinical outcomes from other malignancies, many new treatment choices using targeted agents have been studied in GC. Most targeted therapies focus on the VEGF and epidermal growth factor receptor (EGFR) related indications in advanced GC. Compounds against novel targets, such as mTOR, c-Met (hepatocyte growth factor receptor), and HDAC are also under investigation. Table 1 lists current ongoing phase III trials of targeted agents designed for the treatment of advanced GC.
C Biomed Central

(c) 2012 Liu et al.; licensee BioMed Central Ltd. This is an Open Access article distributed under the terms of the Creative Commons Attribution License (http://creativecommons.org/licenses/by/2.0), which permits unrestricted use, distribution, and reproduction in any medium, provided the original work is properly cited. 
Table 1 Ongoing phase III trials of targeting agents for the treatment of advanced gastric cancer

\begin{tabular}{lllllll}
\hline $\begin{array}{l}\text { ClinicalTrials.gov } \\
\text { Identifier }\end{array}$ & Setting & Location & Masking & $\begin{array}{l}\text { Estimated } \\
\text { enrollment }\end{array}$ & $\begin{array}{l}\text { Primary } \\
\text { endpoint }\end{array}$ & Arm \\
\hline NCT00824785 & $1^{\text {st }}$ line & UK & Open-label & 730 & OS & EOX, EOX + panitumumab \\
\hline NCT01248403 & $2^{\text {nd }}$ line & Germany & Double blind & 500 & OS & Paclitaxel, Paclitaxel + everolimus \\
\hline NCT01170663 & $2^{\text {nd }}$ line & Global & Double blinded & 633 & OS & $\begin{array}{l}\text { Placebo + paclitaxel, } \\
\text { Ramucirumab + paclitaxel }\end{array}$ \\
\hline NCT00450203 & $1^{\text {st }}$ line & UK & Open Label & 1100 & OS & ECX, ECX + Bevacizumab \\
\hline NCT00917384 & $2^{\text {nd }}$ line & Global & Double blinded & 315 & OS & $\begin{array}{l}\text { Placebo + BSC, } \\
\text { Ramucirumab + BSC }\end{array}$ \\
\hline NCT01512745 & $3^{\text {rd } l i n e ~}$ & China & Double blinded & 500 & PFS & Placebo, Apatinib \\
\hline
\end{tabular}

OS, overall survival; PFS, progression-free survival; EOX, epirubicin, oxaliplatin and capecitabine; ECX, epirubicin, cisplatin and capecitabine.

\section{Anti-VEGF/VEGFR Agents}

Angiogenesis, the growth of new blood vessels, is an important aspect of tumorigenesis that not only provides tumor cells with nutrients and oxygen, but additionally serves as a pathway for tumor cells to enter the circulatory system, where subsequent metastasis may occur [7]. Tumor angiogenesis is primarily modulated by VEGF A and the receptors of VEGF (VEGFR) [8]. In GC, VEGF expression is related to tumor aggressiveness and is ultimately an indicator for poor prognosis [9-15]. AntiVEGF agents have recently been developed, including mAbs and TKIs, for the reasons mentioned above.

\section{Bevacizumab}

Bevacizumab is a VEGF A blocking mAb currently under investigation for the treatment of GC. Several phase II trials combining bevacizumab with different chemotherapeutic compounds were conducted on treatment-naive patients with locally advanced or metastatic GC, or with gastroesophageal junction cancer (GEJC), demonstrating results which were initially promising [16-18]. On the basis of results from these phase II studies, a phase III randomized, double-blind, contrast study (AVAGAST) was conducted internationally [19]. This study included 774 patients with previously untreated and locally advanced or metastatic GC or GEJC. Patients were treated with capecitabine and cisplatin in combination with either bevacizumab or a placebo. The median rate of overall survival (OS) was 10.1 months for the placebo group and 12.1 months for the bevacizumab group $(\mathrm{HR}=0.87 ; \mathrm{P}=0.1002)$, failing to meet the primary endpoint; however, significant improvement in progressionfree survival (PFS) and overall response rate (ORR) was noted in the bevacizumab group. In subgroup analysis, OS for the pan-American subgroup was 6.8 months for placebo vs. 11.5 months for bevacizumab $(H R=0.63)$. For European and Asian-Pacific subgroups, OS was 8.6 vs. 11.1 months $(\mathrm{HR}=0.85)$, and 12.1 vs. 13.9 months $(\mathrm{HR}=0.97)$, respectively, with all results favoring bevacizumab. These results indicate that Pan-American patients obtained the greatest benefit from the additional bevacizumab treatment. The subgroup analysis of geographic regions and GC subtypes was further reported in the 2012 American Society of Clinical Oncology (ASCO) gastrointestinal cancers symposium. For both Asian and nonAsian patients, most patients have type $2 \mathrm{GC}(52.1 \%)$ or type 3 (38.3\%) GC, and those with type 2 GC had worse outcome than type 3 GC (median OS 10.3 vs 11.7 months; $\mathrm{HR}=0.82$; $95 \% \mathrm{CI} 0.68-1.00$ ). For non-Asian patients, prognosis is worse than Asian patients (8.0 vs 11.1 months; $\mathrm{HR}=0.68$; $95 \%$ CI 0.53-0.89), and those with GC type 2 (6.5 vs 9.9 months; $\mathrm{HR}=0.68$; $95 \% \mathrm{CI} 0.48-0.97$ ) and type 3 (9.0 vs 11.7 months; $\mathrm{HR}=0.72$; $95 \%$ CI $0.48-1.07$ ) appear to benefit from bevacizumab, making bevacizumab more promising in non-Asian patients [20].

\section{Ramucirumab}

Ramucirumab is a fully humanzed mAb targeting VEGFR2 [21]. Several trials are onging, including a randomized phase II clinical trial of mFOLFOX6 (oxaliplatin, 5-FU, folic acid) chemotherapy plus Ramucirumab versus mFOLFOX6 plus placebo for advanced gastroesophageal adenocarcinoma, a randomized phase III study of paclitaxel with or without Ramucirumab in patients with metastatic gastric adenocarcinoma after failure of first-line therapy with platinum and fluoropyrimidine, and another phase III study of Ramucirumab eing compared with best supportive care (BSC) in patients with gastric cancer and adenocarcinoma.

\section{Apatinib}

Apatinib is a relatively "clean" TKI that selectively targets VEGFR-2 [22]. A randomized, three-arm phase II trial of apatinib as a third-line treatment for patients with advanced GC included 141 patients who received apatinib (850 mg. qd.), apatinib (425 mg. bid.), or a placebo. The study was reported during the 2011 ASCO Annual Meeting, as follows: ORR of 0 (placebo), 6.38 (apatinib $850 \mathrm{mg} \mathrm{qd}$ ), and $13.04 \%$ (apatinib $425 \mathrm{mg}$ bid), respectively [23]. The disease control rate was 10.42, 
42.55 , and $39.13 \%$, respectively. The median PFS was 1.4 , 3.4 , and 3.4 months, respectively; the median OS was 2.5, 4.8 , and 4.3 months, respectively. Primary adverse reactions included hypertension and hand-foot syndrome. A phase III clinical trial comparing apatinib to placebo in a $3^{\text {rd }}$-line setting in advanced GC is currently being conducted in China. The enrollment target is 270. The patients are randomized to apatinib $850 \mathrm{mg}$ qd p.o. or placebo and are treaed until disease progression, intolerable toxicity or withdrawal of consent. The trial was estimated to be finished in June 2012.

\section{Sorafenib}

Sorafenib, originally developed for the treatment of kidney cancer, is a multi-target TKI, targeting VEGFR, plateletderived growth factor receptor (PDGFR), and RAF pathways. It possesses two antineoplastic pathways: one acts directly through the inhibition of tumor proliferation by blocking the RAF/MEK/ERK-mediated cell signaling pathway, and the other indirectly inhibits angiogenesis by blocking VEGFR and PDGFR [24]. Based on the data derived from hepatocellular carcinoma trials, several studies were designed to investigate the role of sorafenib in advanced GC. The results of a phase II study of sorafenib in combination with docetaxel and cisplatin as a treatment for chemo-naive metastatic or local advanced unresectable GC or GEJC patients has been reported [25]. The study enrolled 44 patients who received sorafenib $400 \mathrm{mg}$ bid, in combination with docetaxel $75 \mathrm{mg} / \mathrm{m}^{2} \mathrm{~d} 1$ and cisplatin $75 \mathrm{mg} / \mathrm{m}^{2}$ on day 1 in a 21 -day cycle. The ORR was $41 \%$, the median PFS was 5.8 months, and the median OS was 13.6 months. The authors concluded that sorafenib, combined with docetaxel and cisplatin, was effective and tolerable as a treatment for GC or GEJC . However, this study's results did not indicate superiority over historical data from the docetaxel and cisplatin combination chemotherapy, thereby prompting no further clinical development of sorafenib in GC.

\section{Sunitinib}

Sunitinib blocks angiogenesis by inhibiting targets such as VEGFR, PDGFR, RET and KIT. It is similar to sorafenib in activity, as reported in different tumor types than those observed in sorafenib treatment in both preclinical and clinical settings [26]. In a phase II trial, sunitinib monotherapy was conducted on 52 patients with chemo-refractory advanced GC, resulting in a median OS of 5.8 months, displaying less effectiveness than anticipated [27]. A single-arm, monotherapy phase II study was performed in 78 patients as $2^{\text {nd }}$-line treatment. Two patients $(2.6 \%)$ had partial responses and 25 patients $(32.1 \%)$ had a best response of stable disease for $\geq 6$ weeks. The median PFS was 2.3 months and median OS was 6.8 months. This study showed little clinical value in monotherapy setting [28]. At this time, there is no plan to move forward with sunitinib in further clinical investigations of GC.

\section{Cediranib}

Cediranib, also known as AZD2171, is a highly potent inhibitor of VEGFR-1 and VEGFR-2, which displays activity against c-Kit and PDGFR- $\beta$ [29]. A phase I study of cediranib in combination with cisplatin plus fluoropyrimidine (S-1 or capecitabine) was performed on 14 Japanese patients with treatment-naive advanced GC [30]. This study demonstrated good tolerability with the most common adverse side effects being decreased appetite, fatigue and nausea. Furthermore, preliminary efficacy evaluation showed one confirmed and three unconfirmed partial responses that were ongoing at the time of data cut-off. Further investigation is expected to continue in the future.

\section{EGFR-targeting agents}

Epidermal growth factor receptor (EGFR) exists on the cell surface and is activated by the binding of specific ligands, including epidermal growth factor (EGF) and transforming growth factor alpha. EGFR possesses an intracellular tyrosine kinase domain that, upon activation, may initiate downstream signaling, ultimately resulting in DNA synthesis and cell proliferation. Inhibition of EGFR activation disturbs downstream signaling and prevents tumorigenesis [31]. The prognostic role of EGFR remains controversial, and further investigation is needed [32-37]. Anti-EGFR mAbs and TKIs are currently undergoing clinical trials for GC patients.

\section{Cetuximab}

Cetuximab is a chimeric (mouse/human) mAb targeting to EGFR. Monotherapy with cetuximab for treatment of advanced GC showed minimal activity [38]. Trials investigating cetuximab treatment after first-line chemotherapies were reported with moderate activities [39,40]. In first-line settings (Table 2), in several phase II trials, cetuximab has shown some encouraging results when combined with various chemotherapeutic agents. Discrepancies among these results may be due to the differences in cytotoxic compounds. The phase III trial (EXPAND) will assess the efficacy of cetuximab in combination with cisplatin and capecitabine as a first-line treatment for patients with advanced GC or GEJC. Results are expected to be released later this year.

\section{Panitumumab}

Panitumumab is a fully humanized IgG2 mAb targeting EGFR. Available data for panitumumab in GC is limited. Based on data from metastatic colorectal cancer [52-54], panitumumab was investigated in a dose-finding trial in 
Table 2 Phase II, first-line clinical trials of cetuximab in combination with various chemotherapeutic agents

\begin{tabular}{|c|c|c|c|c|}
\hline Agents & $n$ (tumor site) & RR (\%) & PFS/TTP (month) & OS (month) \\
\hline mFOLFOX6 + cetuximab[41] & $50(\mathrm{GC})$ & 50 & 5.5 & 9.9 \\
\hline Cisplatin + docetaxel + cetuximab[42] & 72 (GC or GEJC) & 41.2 & 5 & 9 \\
\hline Cetuximab + FOLFOX4[43] & $25(\mathrm{GC})$ & 36 & 6.5 & 10.6 \\
\hline Oxaliplatin + irinotecan + cetuximab[44] & $51(\mathrm{GC})$ & 63 & 5.8 & 8.9 \\
\hline Oxaliplatin + folic acid + 5-FU + cetuximab[45] & $52(\mathrm{GC})$ & 65 & 7.6 & 9.5 \\
\hline Oxaliplatin + capecitabine + cetuximab[46] & $44(\mathrm{GC})$ & 52.3 & 6.5 & 11.8 \\
\hline Irinotican + folic acid + 5-FU + cetuximab[47] & 49 (GC or GEJC) & 46 & 9 & 16.5 \\
\hline $\begin{array}{l}\text { Epirubicin + cisplatin +5-FU + cetuximab FOLFOX + cetuximab } \\
\text { Irinotican + cisplatin + cetuximab[48] }\end{array}$ & 245 (GC or GEJC) randomized & 585138 & 5.65 .75 & 10108.6 \\
\hline Cisplatin + 5-FU + LV + cetuximab[49] & $35(\mathrm{GC})$ & 68.6 & 11 & 14.5 \\
\hline Oxaliplatin + irinotecan + cetuximab[50] & $51(\mathrm{GC})$ & 63 & 5.8 & 8.9 \\
\hline Docetaxel + oxaliplatin Docetaxel + oxaliplatin + cetuximab[51] & 150 (GC or GEJC) randomized & 2429 & 4.75 .1 & 98.5 \\
\hline
\end{tabular}

gastric cancer to determine the optimal dosage when combined with EOX regimen: epirubicin, oxaliplatin, and capecitabine. Results indicated that a dose of $9 \mathrm{mg} / \mathrm{kg}$ of panitumumab every 3 weeks, when combined with EOX, meets the acceptable safety profile; it is currently being used in an ongoing phase II/III REAL-3 trial, which is a randomized, open-label trial of the efficacy of EOX with or without Panitumumab as first line therapy for advanced esophagogastric cancer [55].

\section{HER2-targeting agent}

HER2 is a cell membrane surface-bound receptor tyrosine kinase that is normally involved in the signal transduction pathway leading to cell growth and differentiation. The reported expression of HER2 in GC patients and its correlation with prognosis has varied across different studies [34,56-58]. However, pre-clinical trials have shown the efficacy of suppression of tumor growth in human GC over-expressing HER2 by anti-HER2 antibody, making HER2 a potential target $[59,60]$. Clinical investigation in GC with HER 2 targeting by either mAb or TKI has been actively pursued.

\section{Trastuzumab}

Trastuzumab is a HER2 mAb that induces antibodydependent cellular cytotoxicity, inhibits HER2-mediated signaling, and reduces the number of cell surface receptors by increasing endocytosis [61]. A multi-center, randomized, controlled phase III clinical study (ToGA) was reported in 2010, with a total of 3807 advanced GC or GEJC patients enrolled. Of these patients, 810 (21.2\%) were positive for HER2 expression (FISH-amplified or IHC $3+$ and above). Among the 810 patients, 594 were randomly assigned to receive chemotherapy treatment (cisplatin plus 5-FU or capecitabine administered every 3 weeks for a maximum of 6 cycles) or chemotherapy plus trastuzumab treatment (administered at a dose of
$8 \mathrm{mg} / \mathrm{kg}$ on day 1 of the first cycle, followed by $6 \mathrm{mg} / \mathrm{kg}$ every 3 weeks until the event of disease progression, unacceptable toxicity or consent withdrawal). Median OS was 13.8 months in patients assigned to trastuzumab plus chemotherapy, compared with 11.1 months in those assigned to chemotherapy alone (HR 0.74; 95 \% CI $0.60-0.91 ; \mathrm{p}=0.0046)$. The efficacy result translated into a $26 \%$ reduction in the death rate. Adverse effects were comparable between the two treatment groups [4]. Based on the findings of this trial, trastuzumab, in combination with chemotherapy has been approved by US FDA and European Medicines Agency as first-line therapy in HER2 positive GC and GEJC. Notably, HER2-positivity rates were found to be significantly higher in GEJC than GC (33.2\% vs $20.9 \%$; $<<0.001$ ), and in intestinal than diffuse/mixed cancer $(32.2 \%$ vs $6.1 \% / 20.4 \%$; p $<0.001)$ [62].

\section{Lapatinib}

Lapatinib is an oral TKI which inhibits both EGFR and HER2 kinases. The phase II trial of lapatinib monotherapy as first-line therapy in 47 patients with advanced GC demonstrated excellent tolerability and moderate activity (median time to treatment failure was 1.9 months and OS was 4.8 months). Analyzing potential biomarkers revealed that patients with higher HER2 or lower interleukin-8 gene expression levels experienced prolonged OS [63]. In a phase II trial of capecitabine and lapatinib combination as first-line treatment in 58 patients with GC (76\%) or GEJC (24\%), $24 \%$ of patients showed partial responses (17\% confirmed, $7 \%$ unconfirmed), $36 \%$ showed disease stabilization and $26 \%$ showed disease progression [64]. The LOGiC study (Lapatinib Optimization Study in HER2 Positive Gastric Cancer), a phase III global study, designed to evaluate clinical endpoints and safety of chemotherapy plus lapatinib, has reached its accrual goal and is ongoing for follow up. Efficacy data is anticipated to be released in late 2012. An ongoing TYTAN trial is a randomized, 
open-label, phase III study of Lapatinib in combination with Paclitaxel versus Paclitaxel alone in the second line setting of erbB2 amplified advanced GC.

\section{Other targeted agents Everolimus}

The mTOR is involved in several important intracellular signal transduction pathways that regulate cell survival, hyperplasia, apoptosis, and other important physiological functions critical to tumorigenesis and cancer development, thus providing as a potential anti-cancer therapy [65]. The first mTOR targeting agent was everolimus, an oral mTOR serine/threonine kinase inhibitor, whose anti-GC activity was observed in both pre-clinical and phase I studies [65-67]. In a phase II study of everolimus in 53 patients with previously treated metastatic gastric cancer, the results showed that the DCR was $56.0 \%$ (95 \% CI, $41.3 \%$ to $70.0 \%$ ) and median PFS was 2.7 months (95\% CI, 1.6 to 3.0 months). At a median follow-up of 9.6 months, the median OS was 10.1 months (95\% CI, 6.5 to 12.1 months) and good tolerability was noted [68]. Based on the promising results from several phase II trials, an international phase III trial was launched in June 2009. A total of 656 patients with advanced GC previously treated with 1 or 2 lines of systemic chemotherapy from 23 countries were randomly treated with everolimus or BSC plus a placebo. Data released from the 2012 ASCO Gastrointestinal Cancers Symposium indicated that the median OS was 5.4 months with everolimus, vs. 4.3 months with placebo treatment (HR, 0.90; 95 \% CI, 0.75-1.08; P = 0.1244) [69]. Median PFS per local investigator assessment was 1.7 months with everolimus vs. 1.4 months with placebo (HR, 0.66; $95 \%$ CI, 0.56-0.78; $\mathrm{p}<0.0001)$. PFS was improved significantly by everolimus, although the OS was not.

\section{Onartuzumab}

c-Met is an oncogene encoding a membrane tyrosine kinase receptor - hepatocyte growth factor receptor (HGFR). HGFR plays an important role in tumor development through activation of key oncogenic pathways, angiogenesis, and tumor metastasis [70]. In gastric cancer patients, amplification and expression of c-Met often indicates poor prognosis [71-74]. Several types of targeted agents have been developed for c-Met pathway. Onartuzumab is a humanized monoclonal antibody directed against HGFR. A phase II clinical trial of Onartuzumab in combination with mFOLFOX6 in patients with metastatic HER2-negative gastro-esophageal cancer is to be launched soon.

\section{Vorinostat}

Vorinostat is a HDAC inhibitor, also known as suberoylanilide hydroxamic acid. Pre-clinical studies have shown that vorinostat has potential anti-GC activity, due to a synergistic effect exhibited when combined with taxane $[75,76]$. A phase I/II study of vorinostat plus capecitabine and cisplatin is currently recruiting patients for first line treatment of metastatic or recurrent GC.

\section{Future Perspectives}

Contemporary targeted cancer therapy has progressed rapidly over the past decade. Unfortunately, GC remains a major challenge with fewer encouraging targeted treatments than other cancers have. The addition of trastuzumab to combination chemotherapy is now considered a standard first-line treatment for HER2 positive advanced GC patients, and this treatment is still under investigation for potential use in perioperative settings [4]. Lapatinib is currently the most promising new agent for treatment of gastric cancer, in the light of the ToGA trial. Agents targeting human EGFR remain very controversial in treating gastric cancer. Cetuximab has exhibited the potential for GC treatment, which functions by binding to the ubiquitous HER1(EGFR); based on success in treating colorectal cancer patients, cetuximab is currently one of the promising new candidates for treatment of gastric cancer due to its very low mutation rate of K-RAS.

Anti-angiogenic therapy has achieved successful results in several cancer types, including colorectal, hepatocellular, and kidney cancer; however, despite tremendous effort in the past decade, many trials demonstrated only marginal effectiveness over existing treatments. An AVAGAST trial recently released results, indicating negative OS data [19] similar to study results from sorafenib and sunitinib. The primary reason for the disappointing results of anti-angiogenesis treatment is the lack of predictive biomarkers for the investigated drugs. Although biomarkers such as serum VEGFA and microvessel density have repeatedly been cited as potentially useful predictive markers for the effectiveness of anti-angiogenic therapy, they remain unconfirmed by any phase III trial. This makes it difficult to determine which agents are potentially most beneficial to certain patients. Based on the results of the investigations in lung cancer and breast cancer, further clinical analysis of biomarkers may lead to a better understanding of GC outcomes and appropriate treatment selection. Not limited to anti-angiogenic therapy, "Personalizing cancer care" is the goal for all targeting agents, in order to achieve both improved and optimal results based on effective biomarker selection [77].

The majority of existing targeting agents focus on both EGF/VEGF and their receptors, but contemporary research has revealed many new pathways related to tumor angiogenesis and proliferation, providing numerous new potential targets. Trials are already underway to test potential targeting agents focusing on the downstream components of VEGFR/EGFR, such as inhibitors of mTOR, c-Met, and 
HDAC. The phase III trial of everolimus has reported prolonged PFS at ASCO Gastrointestinal Cancers Symposium this year.

Drug resistance is a critical issue in the development of targeted agents. Effective treatment may involve a combination of different targeted agents, chemotherapies, or it may require the use of target agents as part of a complex approach to cancer treatment utilizing multiple modalities.

\section{Abbreviations}

GC: Gastric cancer; 5-FU: 5-fluorouracil; HER2: Human epidermal growth factor receptor 2; VEGF: ,Vascular endothelial growth factor;

mTOR: Mammalian target of rapamycin; HDAC: Histone deacetylase; VEGFR: Receptor of vascular endothelia growth factor; MAb: Monoclonal antibody; TKI: Tyrosine kinase inhibitor; GEJC: Gastro-esophageal junction cancer; ASCO: American Society of Clinical Oncology; OS: Overall survival; PFS: Progression-free survival; ORR: Overall response rate; DCR: Disease control rate; PDGFR: Platelet derived growth factor receptor; EGFR: Epidermal growth factor receptor; EGF: Epidermal growth factor; BSC: Best supportive care.

\section{Competing interests}

The authors declare that they have no competing interests.

\section{Author details}

${ }^{1}$ Department of Medical Oncology, Fudan University Shanghai Cancer Center, Shanghai 200032, China. ${ }^{2}$ Department of Oncology, Shanghai Medical College, Shanghai 200032, China. ${ }^{3}$ Department of Medical Oncology Xuhui District central Hospital, Shanghai 200031, China.

\section{Authors' contributions}

All authors participated in the drafting and editing of the manuscript. All authors read and approved the final manuscript.

Received: 10 April 2012 Accepted: 18 June 2012

Published: 18 June 2012

\section{References}

1. Ferlay J, Shin HR, Bray F, Forman D, Mathers C, Parkin DM: Estimates of worldwide burden of cancer in 2008: GLOBOCAN 2008. Int J Cancer 2010, 127:2893-2917.

2. Crew KD, Neugut Al: Epidemiology of upper gastrointestinal malignancies. Semin Oncol 2004, 31:450-464.

3. Wagner AD, Unverzagt S, Grothe W, Kleber G, Grothey A, Haerting J, Fleig WE: Chemotherapy for advanced gastric cancer. Cochrane Database Syst Rev 2010, [http://onlinelibrary.wiley.com/doi/10.1002/14651858.CD004064. pub3/abstract].

4. Bang YJ, Van Cutsem E, Feyereislova A, Chung HC, Shen L, Sawaki A, Lordick F, Ohtsu A, Omuro Y, Satoh T, et al: Trastuzumab in combination with chemotherapy versus chemotherapy alone for treatment of HER2positive advanced gastric or gastro-oesophageal junction cancer (ToGA): a phase 3, open-label, randomised controlled trial. Lancet 2010, 376: 687-697.

5. Yuan RK, David, Andrea Berg WL: Targeting tumorigenesis: development and use of mTOR inhibitors in cancer therapy. $J$ HEMATOL ONCOL 2009, 2:45.

6. Tan J, Cang S, Ma Y, Petrillo RL, Liu D: Novel histone deacetylase inhibitors in clinical trials as anti-cancer agents. J Hematol Oncol 2010, 3:5.

7. Folkman J: Angiogenesis. Annu Rev Med 2006, 57:1-18.

8. Ferrara N, Gerber HP, LeCouter J: The biology of VEGF and its receptors. Nat Med 2003, 9:669-676.

9. Kolev Y, Uetake H, lida S, Ishikawa T, Kawano T, Sugihara K: Prognostic significance of VEGF expression in correlation with COX-2, microvessel density, and clinicopathological characteristics in human gastric carcinoma. Ann Surg Oncol 2007, 14:2738-2747.

10. Suzuki S, Dobashi Y, Hatakeyama Y, Tajiri R, Fujimura T, Heldin CH, Ooi A: Clinicopathological significance of platelet-derived growth factor (PDGF)$B$ and vascular endothelial growth factor-A expression, PDGF receptor- beta phosphorylation, and microvessel density in gastric cancer. $B M C$ Cancer 2010, 10:659.

11. Shi H, Xu JM, Hu NZ, Xie HJ: Prognostic significance of expression of cyclooxygenase-2 and vascular endothelial growth factor in human gastric carcinoma. World I Gastroenterol 2003, 9:1421-1426.

12. Lieto E, Ferraraccio F, Orditura M, Castellano P, Mura AL, Pinto M, Zamboli A, De Vita F, Galizia G: Expression of vascular endothelial growth factor (VEGF) and epidermal growth factor receptor (EGFR) is an independent prognostic indicator of worse outcome in gastric cancer patients. Ann Surg Oncol 2008, 15:69-79.

13. Maeda K, Chung YS, Ogawa Y, Takatsuka S, Kang SM, Ogawa M, Sawada T, Sowa M: Prognostic value of vascular endothelial growth factor expression in gastric carcinoma. Cancer 1996, 77:858-863.

14. Kim SE, Shim KN, Jung SA, Yoo K, Lee JH: The clinicopathological significance of tissue levels of hypoxia-inducible factor-1alpha and vascular endothelial growth factor in gastric cancer. Gut Liver 2009, 3:88-94.

15. Song ZJ, Gong P, Wu YE: Relationship between the expression of iNOS, VEGF, tumor angiogenesis and gastric cancer. World J Gastroenterol 2002, 8:591-595.

16. Shah MA, Ramanathan RK, Ilson DH, Levnor A, D'Adamo D, O'Reilly E, Tse A, Trocola R, Schwartz L, Capanu M, et al: Multicenter phase II study of irinotecan, cisplatin, and bevacizumab in patients with metastatic gastric or gastroesophageal junction adenocarcinoma. J Clin Oncol 2006, 24:5201-5206.

17. Shah MA, Jhawer M, Ilson DH, Lefkowitz RA, Robinson E, Capanu M, Kelsen DP: Phase II study of modified docetaxel, cisplatin, and fluorouracil with bevacizumab in patients with metastatic gastroesophageal adenocarcinoma. J Clin Oncol 2011, 29:868-874.

18. El-Rayes BF, Zalupski M, Bekai-Saab T, Heilbrun LK, Hammad N, Patel B, Urba S, Shields AF, Vaishampayan U, Dawson S, et al: A phase II study of bevacizumab, oxaliplatin, and docetaxel in locally advanced and metastatic gastric and gastroesophageal junction cancers. Ann Oncol 2010, 21:1999-2004.

19. Ohtsu A, Shah MA, Van Cutsem E, Rha SY, Sawaki A, Park SR, Lim HY, Yamada Y, Wu J, Langer B, et al: Bevacizumab in combination with chemotherapy as first-line therapy in advanced gastric cancer: a randomized, double-blind, placebo-controlled phase III study. J Clin Oncol 2011, 29:3968-3976.

20. Shah MA, Van Cutsem E, Kan Y, Dakhil SR, Satoh T, Chin K, Bang Y, Bu L, Bilic G, Ohtsu A: Survival analysis according to disease subtype in AVAGAST: First-line capecitabine and cisplatin plus bevacizumab (bev) or placebo in patients (pts) with advanced gastric cancer. J Clin Oncol(Meeting Abstracts) 2012, 30(5). [http://www.asco.org/ASCOv2/Meetings/Abstracts? \&vmview=abst_detail_view\&conflD=115\&abstract|D=88735].

21. Krupitskaya Y, Wakelee HA: Ramucirumab, a fully human mAb to the transmembrane signaling tyrosine kinase VEGFR-2 for the potential treatment of cancer. Curr Opin Investig Drugs 2009, 10:597-605.

22. Tian S, Quan H, Xie C, Guo H, Lu F, XU Y, Li J, Lou L: YN968D1 is a novel and selective inhibitor of vascular endothelial growth factor receptor-2 tyrosine kinase with potent activity in vitro and in vivo. Cancer Sci 2011, 102:1374-1380.

23. Li J, Qin $S$, Xu J, Guo WJ, Xiong JP, Bai Y, Sun G, Yang Y, Wang L, Xu N, et al: A randomized, double-blind, multicenter, phase, three-arm, placebocontrol study of apatinib as third-line treatment in patients with metastatic gastric carcinoma. J Clin Oncol (Meeting Abstracts) 2011, 29:4019.

24. Wilhelm SM, Adnane L, Newell P, Villanueva A, Llovet JM, Lynch M: Preclinical overview of sorafenib, a multikinase inhibitor that targets both Raf and VEGF and PDGF receptor tyrosine kinase signaling. Mol Cancer Ther 2008, 7:3129-3140.

25. Sun W, Powell M, O'Dwyer PJ, Catalano P, Ansari RH 3rd BAB: Phase II study of sorafenib in combination with docetaxel and cisplatin in the treatment of metastatic or advanced gastric and gastroesophageal junction adenocarcinoma: ECOG 5203. J Clin Oncol 2010, 28:2947-2951.

26. Chow LQ, Eckhardt SG: Sunitinib: from rational design to clinical efficacy. J Clin Oncol 2007, 25:884-896.

27. Moehler M, Mueller A, Hartmann JT, Ebert MP, Al-Batran SE, Reimer P, Weihrauch M, Lordick F, Trarbach T, Biesterfeld S, et al: An open-label, multicentre biomarker-oriented AIO phase II trial of sunitinib for patients with chemo-refractory advanced gastric cancer. Eur J Cancer 2011, 47:1511-1520 
28. Bang YJ, Kang YK, Kang WK, Boku N, Chung HC, Chen JS, Doi T, Sun Y, Shen L, Qin S, et al: Phase II study of sunitinib as second-line treatment for advanced gastric cancer. Invest New Drugs 2011, 29:1449-1458.

29. Lindsay CR, MacPherson IR, Cassidy J: Current status of cediranib: the rapid development of a novel anti-angiogenic therapy. Future Oncol 2009, 5:421-432

30. Satoh T, Yamada Y, Muro K, Hayashi H, Shimada Y, Takahari D, Taku K, Nakajima TE, Shi $X$, Brown KH, et al: Phase I study of cediranib in combination with cisplatin plus fluoropyrimidine (S-1 or capecitabine) in Japanese patients with previously untreated advanced gastric cancer. Cancer Chemother Pharmacol 2011, 69(2):439-446.

31. Arteaga C: Targeting HER1/EGFR: a molecular approach to cancer therapy. Semin Oncol 2003, 30:3-14

32. Matsubara J, Nishina T, Yamada Y, Moriwaki T, Shimoda T, Kajiwara T, Nakajima TE, Kato K, Hamaguchi T, Shimada Y, et al: Impacts of excision repair cross-complementing gene 1 (ERCC1), dihydropyrimidine dehydrogenase, and epidermal growth factor receptor on the outcomes of patients with advanced gastric cancer. Br J Cancer 2008, 98:832-839.

33. Nicholson RI, Gee JM, Harper ME: EGFR and cancer prognosis. Eur J Cancer 2001, 37(Suppl 4):S9-15.

34. Matsubara J, Yamada $Y$, Hirashima Y, Takahari D, Okita NT, Kato K, Hamaguchi T, Shirao K, Shimada Y, Shimoda T: Impact of insulin-like growth factor type 1 receptor, epidermal growth factor receptor, and HER2 expressions on outcomes of patients with gastric cancer. Clin Cancer Res 2008, 14:3022-3029.

35. Mammano E, Belluco C, Sciro M, Mencarelli R, Agostini M, Michelotto M, Marchet A, Nitti D: Epidermal growth factor receptor (EGFR): mutational and protein expression analysis in gastric cancer. Anticancer Res 2006, 26:3547-3550.

36. Galizia $G$, Lieto $E$, Orditura M, Castellano P, Mura AL, Imperatore V, Pinto M, Zamboli A, De Vita F, Ferraraccio F: Epidermal growth factor receptor (EGFR) expression is associated with a worse prognosis in gastric cancer patients undergoing curative surgery. World J Surg 2007, 31:1458-1468

37. Gamboa-Dominguez A, Dominguez-Fonseca C, Quintanilla-Martinez $L$, Reyes-Gutierrez E, Green D, Angeles-Angeles A, Busch R, Hermannstadter C, Nahrig J, Becker KF, et al: Epidermal growth factor receptor expression correlates with poor survival in gastric adenocarcinoma from Mexican patients: a multivariate analysis using a standardized immunohistochemical detection system. Mod Pathol 2004, 17:579-587.

38. Chan JA, Blaszkowsky LS, Enzinger PC, Ryan DP, Abrams TA, Zhu AX, Temel JS, Schrag D, Bhargava P, Meyerhardt JA, et al: A multicenter phase II trial of single-agent cetuximab in advanced esophageal and gastric adenocarcinoma. Ann Oncol 2011, 22:1367-1373.

39. Schoennemann KR, Bjerregaard JK, Hansen TP, De Stricker K, Gjerstorff MF, Jensen HA, Vestermark LW, Pfeiffer P: Biweekly cetuximab and irinotecan as second-line therapy in patients with gastro-esophageal cancer previously treated with platinum. Gastric Cancer 2011, 14:219-225.

40. Li J, Liu X, Wang BY, Guo WJ, Yin JL, Zhu XD, Zhang J, Liu T: Phase II study of cetuximab in combination with modified FOLFIRI in patients with advanced gastric cancer who failed first-line chemotherapy (EFFI study). J Clin Oncol (Meeting Abstracts) 2010, 28(15):4107. [http://www.asco.org/ASCOv2/ Meetings/Abstracts?\&vmview=abst detail view\&conflD=74\&abstractID=47762].

41. Han SW, Oh DY, Im SA, Park SR, Lee KW, Song HS, Lee NS, Lee KH, Choi IS, Lee $\mathrm{MH}$, et al: Phase II study and biomarker analysis of cetuximab combined with modified FOLFOX6 in advanced gastric cancer. $\mathrm{Br} J$ Cancer 2009, 100:298-304.

42. Pinto C, Di FF, Barone C, Siena S, Falcone A, Cascinu S, Rojas LFL, Stella G, Schinzari $G$, Artale $S$, et al: Phase II study of cetuximab in combination with cisplatin and docetaxel in patients with untreated advanced gastric or gastro-oesophageal junction adenocarcinoma (DOCETUX study). $\mathrm{Br}$ J Cancer 2009, 101:1261-1268.

43. Shi M, Ji J, Wu J, Ma T, Liu Y, Zhou CF, Su Y, Ye ZB, Zhang J, Zhu ZG: Cetuximab Combined With FOLFOX4 as the First-Line Treatment for Advanced Gastric Cancer: Report of 25 Cases from a Single Institution. Hepatogastroenterology 2012, 59. doi:LID - 10.5754/hge11874.

44. Woll E, Greil R, Eisterer W, Bechter O, Fridrik MA, Grunberger B, Zabernigg A, Mayrbaurl B, Russ G, Dlaska M, et al: Oxaliplatin, irinotecan and cetuximab in advanced gastric cancer. A multicenter phase II trial (Gastric-2) of the Arbeitsgemeinschaft Medikamentose Tumortherapie (AGMT). Anticancer Res 2011, 31:4439-4443.

45. Lordick F, Luber B, Lorenzen S, Hegewisch-Becker S, Folprecht G, Woll E, Decker T, Endlicher E, Rothling N, Schuster T, et al: Cetuximab plus oxaliplatin/leucovorin/5-fluorouracil in first-line metastatic gastric cancer: a phase II study of the Arbeitsgemeinschaft Internistische Onkologie (AIO). Br J Cancer 2010, 102:500-505.

46. Kim C, Lee JL, Ryu MH, Chang HM, Kim TW, Lim HY, Kang HJ, Park YS, Ryoo BY, Kang YK: A prospective phase II study of cetuximab in combination with XELOX (capecitabine and oxaliplatin) in patients with metastatic and/or recurrent advanced gastric cancer. Invest New Drugs 2011, 29:366-373.

47. Moehler M, Mueller A, Trarbach T, Lordick F, Seufferlein T, Kubicka S, Geissler M, Schwarz S, Galle PR, Kanzler S: Cetuximab with irinotecan, folinic acid and 5-fluorouracil as first-line treatment in advanced gastroesophageal cancer: a prospective multi-center biomarker-oriented phase II study. Ann Oncol 2011, 22:1358-1366.

48. Enzinger PC, Burtness B, Hollis D, Niedzwiecki D, llson D, Benson AB, Mayer RJ, Goldberg RM: A randomized phase II study of three standard chemotherapy regimens (ECF, IC, FOLFOX) plus cetuximab in metastatic esophageal and GE junction cancer. J Clin Oncol (Meeting Abstracts) 2010, 4006:28-4006. CALGB 80403/ECOG 1206.

49. Yeh K, Hsu C, Hsu C, Lin C, Shen Y, Wu S, Chiou T, Chao Y, Cheng A: Phase II study of cetuximab plus weekly cisplatin and 24-hour infusion of high-dose 5-fluorouracil and leucovorin for the first-line treatment of advanced gastric cancer. J Clin Oncol (Meeting Abstracts) 2009, 27-4567. [http://www.asco.org/ASCOv2/Meetings/Abstracts? \&vmview=abst_detail_view\&conflD=65\&abstractID=32650].

50. Woell E, Greil R, Eisterer W, Fridrik M, Grünberger B, Zabernigg A, Mayrbäurl B, Russ G, Thaler J: Oxaliplatin, irinotecan, and cetuximab in advanced gastric cancer. First efficacy results of a multicenter phase II trial (AGMT Gastric-2) of the Arbeitsgemeinschaft Medikamentoese Tumortherapie (AGMT). J Clin Oncol (Meeting Abstracts) 2009, :27-4538. [http:/www.asco.org/ASCOv2/ Meetings/Abstracts?\&vmview=abst_detail_view\&conflD=65\&abstract|D=31014].

51. Richards DA, Kocs DM, Spira Al, McCollum AD, Boehm KA, Zhan F, Asmar L: Results of docetaxel plus oxaliplatin (DOCOX) with or without cetuximab in patients with metastatic gastric and/or gastroesophagel junction adenocarcinoma: Results of a randomized phase II study. J Clin Oncol (Meeting Abstracts) 2011, 29:4015. [http://www.asco.org/ASCOv2/Meetings/ Abstracts?\&vmview=abst_detail_view\&conflD=102\&abstract|D=79320].

52. Douillard JY, Siena S, Cassidy J, Tabernero J, Burkes R, Barugel M, Humblet $Y$, Bodoky G, Cunningham D, Jassem J, et al: Randomized, phase III trial of panitumumab with infusional fluorouracil, leucovorin, and oxaliplatin (FOLFOX4) versus FOLFOX4 alone as first-line treatment in patients with previously untreated metastatic colorectal cancer: the PRIME study. J Clin Oncol 2010, 28:4697-4705.

53. Peeters M, Price TJ, Cervantes A, Sobrero AF, Ducreux M, Hotko Y, Andre T, Chan E, Lordick F, Punt CJ, et al: Randomized phase III study of panitumumab with fluorouracil, leucovorin, and irinotecan (FOLFIRI) compared with FOLFIRI alone as second-line treatment in patients with metastatic colorectal cancer. J Clin Oncol 2010, 28:4706-4713.

54. Di NF, Martini M, Molinari F, Sartore-Bianchi A, Arena S, Saletti P, De Dosso S, Mazzucchelli L, Frattini M, Siena S, et al: Wild-type BRAF is required for response to panitumumab or cetuximab in metastatic colorectal cancer. J Clin Oncol 2008, 26:5705-5712.

55. Okines AF, Ashley SE, Cunningham D, Oates J, Turner A, Webb J, Saffery C, Chua YJ, Chau I: Epirubicin, oxaliplatin, and capecitabine with or without panitumumab for advanced esophagogastric cancer: dose-finding study for the prospective multicenter, randomized, phase II/III REAL-3 trial. J Clin Oncol 2010, 28:3945-3950.

56. Grabsch H, Sivakumar S, Gray S, Gabbert HE, Muller W: HER2 expression in gastric cancer: Rare, heterogeneous and of no prognostic value conclusions from 924 cases of two independent series. Cell Oncol 2010, 32:57-65.

57. Yu GZ, Chen Y, Wang JJ: Overexpression of Grb2/HER2 signaling in Chinese gastric cancer: their relationship with clinicopathological parameters and prognostic significance. J Cancer Res Clin Oncol 2009, 135:1331-1339.

58. Allgayer $\mathrm{H}$, Babic R, Gruetzner KU, Tarabichi A, Schildberg FW, Heiss MM: c-erbB-2 is of independent prognostic relevance in gastric cancer and is associated with the expression of tumor-associated protease systems. J Clin Oncol 2000, 18:2201-2209.

59. Fujimoto-Ouchi K, Sekiguchi F, Yasuno H, Moriya Y, Mori K, Tanaka Y: Antitumor activity of trastuzumab in combination with chemotherapy in human gastric cancer xenograft models. Cancer Chemother Pharmacol 2007, 59:795-805. 
60. Matsui $Y$, Inomata M, Tojigamori M, Sonoda K, Shiraishi N, Kitano S: Suppression of tumor growth in human gastric cancer with HER2 overexpression by an anti-HER2 antibody in a murine model. Int $\mathrm{J}$ Oncol 2005, 27:681-685.

61. Sliwkowski MX, Lofgren JA, Lewis GD, Hotaling TE, Fendly BM, Fox JA: Nonclinical studies addressing the mechanism of action of trastuzumab (Herceptin). Semin Oncol 1999, 26:60-70.

62. Bang Y, Chung H, Xu J, Lordick F, Sawaki A, Lipatov O, Al-Sakaff N, See C, Rueschoff J, Van Cutsem E: Pathological features of advanced gastric cancer (GC): Relationship to human epidermal growth factor receptor 2 (HER2) positivity in the global screening programme of the ToGA trial. 2009: 27-4556. [http://www.asco.org/ASCOv2/Meetings/Abstracts? \&vmview=abst_detail_view\&confID=65\&abstract|D=32974].

63. Iqbal S, Goldman B, Fenoglio-Preiser CM, Lenz HJ, Zhang W, Danenberg KD, Shibata SI, Blanke CD: Southwest Oncology Group study S0413: a phase II trial of lapatinib (GW572016) as first-line therapy in patients with advanced or metastatic gastric cancer. Ann Oncol 2011, 22:2610-2615.

64. Lenz H, Zhang W, Kemner AM: Lapatinib + capecitabine in advanced gastric cancer: An open-label phase II study of non ERBB2-targeted disease. Ann Oncol 2010, 21:817.

65. Guertin DA, Sabatini DM: Defining the role of mTOR in cancer. Cancer Cell 2007, 12:9-22

66. Lim T, Lee J, Lee DJ, Lee HY, Han B, Baek KK, Ahn HK, Lee SJ, Park SH, Park $\mathrm{JO}$, et al: Phase I trial of capecitabine plus everolimus (RAD001) in patients with previously treated metastatic gastric cancer. Cancer Chemother Pharmacol 2011, 68:255-262.

67. Xu B, Wu Y, Shen L, Ye D, Jappe A, Cherfi A, Wang H, Yuan R: Two-doselevel confirmatory study of the pharmacokinetics and tolerability of everolimus in Chinese patients with advanced solid tumors. J Hematol Oncol 2011, 4:3.

68. Doi T, Muro K, Boku N, Yamada Y, Nishina T, Takiuchi H, Komatsu Y, Hamamoto Y, Ohno N, Fujita Y, et al: Multicenter phase II study of everolimus in patients with previously treated metastatic gastric cancer. J Clin Oncol 2010, 28:1904-1910.

69. Van Cutsem E, Yeh K, Bang Y, Shen L, Ajani JA, Bai Y, Chung HC, Pan H, Chin $\mathrm{K}$, Muro $\mathrm{K}$, et al: Phase III trial of everolimus (EVE) in previously treated patients with advanced gastric cancer (AGC): GRANITE-1. J Clin Oncol (Meeting Abstracts) 2012, 30. [http://www.asco.org/ASCOv2/Meetings/ Abstracts?\&vmview=abst_detail_view\&conflD=115\&abstractID=87843].

70. Appleman LJ: MET signaling pathway: a rational target for cancer therapy. J Clin Oncol 2011, 29:4837-4838.

71. Lee J, Seo JW, Jun HJ, Ki CS, Park SH, Park YS, Lim HY, Choi MG, Bae JM, Sohn TS, et al: Impact of MET amplification on gastric cancer: possible roles as a novel prognostic marker and a potential therapeutic target Oncol Rep 2011, 25:1517-1524.

72. Graziano F, Galluccio N, Lorenzini P, Ruzzo A, Canestrari E, D'Emidio S, Catalano V, Sisti V, Ligorio C, Andreoni F, et al: Genetic activation of the MET pathway and prognosis of patients with high-risk, radically resected gastric cancer. J Clin Oncol 2011, 29:4789-4795.

73. Lennerz JK, Kwak EL, Ackerman A, Michael M, Fox SB, Bergethon K, Lauwers GY, Christensen JG, Wilner KD, Haber DA, et al: MET amplification identifies a small and aggressive subgroup of esophagogastric adenocarcinoma with evidence of responsiveness to crizotinib. J Clin Oncol 2011, 29:4803-4810.

74. Zhao J, Zhang X, Xin Y: Up-regulated expression of Ezrin and c-Met proteins are related to the metastasis and prognosis of gastric carcinomas. Histol Histopathol 2011, 26(9):1111-1120.

75. Claerhout S, Lim JY, Choi W, Park YY, Kim K, Kim SB, Lee JS, Mills GB, Cho JY: Gene expression signature analysis identifies vorinostat as a candidate therapy for gastric cancer. PLoS One 2011, 6:e24662.

76. Chang H, Rha SY, Jeung HC, Jung JJ, Kim TS, Kwon HJ, Kim BS, Chung HC: Identification of genes related to a synergistic effect of taxane and suberoylanilide hydroxamic acid combination treatment in gastric cancer cells. J Cancer Res Clin Oncol 2010, 136(12):1901-1913.

77. Javle MH, Chung-Tsen: Recent advances in gastrointestinal oncology updates and insights from the 2009 annual meeting of the American Society of Clinical Oncology. J HEMATOL ONCOL 2010, 3:11.

doi:10.1186/1756-8722-5-31

Cite this article as: Liu et al:: Novel targeted agents for gastric cancer. Journal of Hematology \& Oncology 2012 5:31.

\section{Submit your next manuscript to BioMed Central and take full advantage of:}

- Convenient online submission

- Thorough peer review

- No space constraints or color figure charges

- Immediate publication on acceptance

- Inclusion in PubMed, CAS, Scopus and Google Scholar

- Research which is freely available for redistribution 